\title{
Libraries 2000: Transforming Libraries Using Document Delivery, Needs Assessment, and Networked Resources
}

\section{Jane P. Kleiner and Charles A. Hamaker}

The Louisiana State University and Agricultural and Mechanical College (LSU) Libraries are transforming traditional research library practices by containing serial expenditures, implementing network developments, and attracting grant support. This paper describes three projects designed to utilize document delivery and electronic access to expand collections, identify faculty journal needs, and share resources among Louisiana libraries. It reports the results of document-delivery pilots and journal needs assessment surveys of LSU science and social sciences faculty and compares findings. Data on the use and cost of subsidized document delivery are included. The article also summarizes the libraries' grant activities, which have been awarded more than $\$ 6$ million in three years.

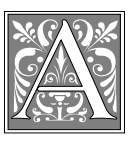

$\mathrm{s}$ the world enters the twentyfirst century, academic librarians must become entrepreneurs to meet the needs of electronically adept faculty, students, and staff. Libraries must anticipate a clientele with higher expectations. These are children of the electronic age who were rocked to sleep by television, cut their teeth on video, had "toy" computers as toddlers, and did their schoolwork at more sophisticated workstations than existed a decade ago.

Online catalogs displaying bibliographic records are not sufficient.
Tomorrow's users (and today's) need access to electronic indexes and abstracts, full-text data collections, and graphics. They want the virtual library now, and the technology exists to create it. Some states, including Louisiana, are transforming traditional libraries into information centers; a few are pushing into the future by sharing resources among all types of libraries.

Expanded access to electronic resources is costly, but even libraries in economically deprived states can achieve that goal. By redesigning traditional practices, attracting grant funds, and gaining

Jane P. Kleiner is Head of Remote Document Services and Grants in the LSU Libraries at Louisiana State University and A \& M College; e-mail: notjpk@lsuvm.sncc.lsu.edu. Charles A. Hamaker is Assistant Dean of Collection Development in the LSU Libraries at Louisiana State University and A \& M College; e-mail:notcah@unix1.sncc.lsu.edu. 
improved state support, libraries can move forward effectively. This paper describes steps taken by the Louisiana State University and Agricultural and $\mathrm{Me}$ chanical College (LSU) Libraries to jumpstart the next century. It focuses on three projects designed to:

- utilize document delivery and electronic access to expand traditional collections;

- identify faculty members' journal needs for research and instruction;

- share resources among academic, public, special, and $\mathrm{K}-12$ school libraries.

LSU's 42-month document-delivery (DD) program and its impact on the libraries' collections are described. The results of journal needs assessments of science and social sciences faculty are reported and compared with articles ordered along with use and cost data for subsidized DD from the 3.5-year project. Finally, LSU's approaches to attracting more than $\$ 6$ million in state and federal grant funds, public subsidies, and state appropriations to develop library networks are summarized. Implementation guidelines are outlined.

\section{Profile of Louisiana and the LSU Libraries}

Profiles of Louisiana and the flagship university underscore the plight facing higher education when these projects were initiated. The state is divided into sixty-four parishes (counties), with a total population of $4,219,973$. It is a mix of cultures: white, Protestant, and AngloSaxon in the north; French, Roman Catholic, and nonwhite in the south. It is largely rural; only 68 percent of the population have graduated from high school. At 16 percent, Louisiana's illiteracy rate is the nation's worst. ${ }^{1}$ The state has not recovered from a mid-eighties recession caused by the domestic oil industry collapse. The employment rate remains below that of 1981. Louisiana ranks forty-fifth among the states in personal income and fortyseventh in median household income. ${ }^{2}$
LSU is designated by the Board of Regents as the state's only comprehensive university and by the Carnegie Foundation as a Research University I, placing it in the top two percent of higher education institutions. It supports 206 degree programs including fifty-six doctoral programs. ${ }^{3}$ According to the National Research Council, LSU is in the top thirty universities in federal, state, and private expenditures. With 27,000 students, including 4,000 graduate students, it is one of twenty-five universities designated as a land-grant and sea-grant institution, and is actively seeking space-grant status. $^{4}$

\section{At 16 percent, Louisiana's illiteracy rate is the nation's worst. ${ }^{1}$}

The LSU Libraries contain 2.7 million volumes, 3.5 million microforms, and manuscript collections of 12 million items. It is a member of the Association of Research Libraries (ARL), the Association of Southeastern Research Libraries, the Southeastern Library Network, the Louisiana Academic Library Information Network Consortium, the Coalition for Networked Information, and OCLC through SOLINET. Until these projects, the libraries had been at a standstill materials budget for a decade, relieved by occasional bursts of one-time funds.

\section{From Acquisition to Access}

Libraries serve as the front line of America's information system. ${ }^{5}$ Their collections define their purpose and standing. A "good" collection has historical depth and comprehensive coverage, and supports institutional programs with a modicum of interlibrary loan (ILL) use. However, this approach is under attack today. Journal prices have created a crisis because few budgets can keep pace with inflated costs and changing needs. A spring 1995 survey reported that materials budgets in ARL are being 


\begin{tabular}{|c|c|c|}
\hline \multicolumn{3}{|c|}{ 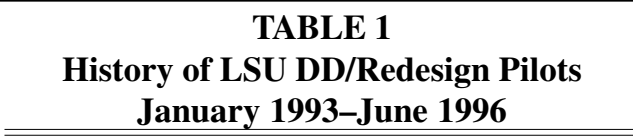 } \\
\hline 1st Pilot & Chemistry & Apr. 1993 \\
\hline 2nd Pilot & $\begin{array}{l}\text { Geography } \\
\text { \& Anthropology }\end{array}$ & Nov. 1993 \\
\hline 3rd Pilot & Science/Technology Depts. & Fall 1994 \\
\hline 4th Pilot & LSU UnCover gateway & Fall 1995 \\
\hline 5th Pilot & Social Science Depts. & Fall 1995 \\
\hline
\end{tabular}

prices increased 138 percent. ${ }^{10}$

The LSU Libraries historically divided materials funds into $\$ 1$ million for books and $\$ 1$ million for subscriptions until the 1980 s when international journal prices began eroding library purchasing power. By 1992, after three rounds of cancellations, faculty were resisting further reviews and cancellations. With serial costs climbing to 85 percent of the materials budget, LSU needed "reconceptualized" due to the serials crisis and electronic resource demands. ${ }^{6}$

Budgets are strained to provide electronic information and the equipment to access it, and fund increasing costs for ILL and DD to acquire titles and articles not owned. Materials budgets fund DD in half of the ARL libraries surveyed. ${ }^{7}$ These reallocations decrease funding for traditional materials. Further complicating the budget picture is the fluctuation of the American dollar against foreign currencies. Decreases in the dollar's value from previous payment seasons have exacerbated higher journal prices. ${ }^{8}$ International publishers' titles represent a significant portion of serial purchases, especially in the sciences, technology, and medicine.

\section{Traditional Collection Development Approaches}

Libraries have opted for various solutions to these problems. Skyrocketing subscription prices have greatly impacted budgets; containment of journal collections has been a primary tool used to address the problem. Many libraries have reduced expenditures by utilizing the results of circulated title lists to gain faculty input in order to cancel or retain titles. Others have reduced staff, curtailed special collections expenditures, canceled memberships, and eliminated nonessential costs. Reduced purchases also have resulted. ${ }^{9}$ An ARL monograph and serials study revealed that from 1986 to 1996 , monograph purchases decreased 23 percent and serial purchases 8 percent, whereas serial a new approach to the crisis.

Following is the methodology designed by the LSU Libraries to curtail expenditures after repeated cancellations failed to contain costs. Data from 3.5 years of DD use, traditional interlibrary borrowing (ILB), and faculty needs assessments now are employed to redefine LSU's journal collection and to expand information resources. Pilot study findings are provided and ongoing activities described. Table 1 depicts the history of DD use and the time line utilized for the pilot studies. This model now is being tested by other libraries.

\section{Literature Review}

The challenges journal collections present are not new. They cost too much. There are too few, require too much space, and are too costly to process, with pricing the paramount issue. Astle and Hamaker reviewed a century of pricing issues and journal problems, ${ }^{11}$ including currency differentials and citation analysis ${ }^{12}$ which resulted in American libraries paying twenty times more for titles than German buyers. ${ }^{13}$ The "let America pay for it" attitude continued until American library associations issued a joint resolution urging libraries to cancel "excessively expensive journals" unless publishers reduced prices. ${ }^{14}$ German authors, publishers, and librarians then agreed to "state the subscription prices in advance" and reduce content and price 20 percent. ${ }^{15}$

Pricing issues again became critical in the 1970s. Berkeley's University of Cali- 
fornia Biology Library reported that half the budget supported 194 high-cost journals (5\% of the titles). ${ }^{16}$ North American Serials Interest Group (NASIG) 1987 conference papers confirmed that finding. Hamaker reported that 10 percent of LSU's journals claimed 60 percent of serials costs. This time the expensive titles were produced by international scientific publishers ${ }^{17}$ who were responsible for 43 percent of increased costs, but only 4 percent of the subscriptions at LSU. ${ }^{18}$ Price increases, fluctuating currencies, ${ }^{19}$ distribution arrangements, and a nominal growth in the literature drove increases as high as 66 percent from 1985 to $1986 .{ }^{20}$

Academics' "publish or perish" mandate also has contributed to increasing costs, with journals often created to provide space for aspiring professors. After

\section{Academics' "publish or perish" mandate also has contributed to increasing costs, with journals often created to provide space for aspiring professors.}

surveying 200 English-language psychology journals, two psychology professors concluded that only 70 percent should survive based on content quality. ${ }^{21}$ A January 1996 College \& Research Libraries article evaluated the pricing literature and suggested that the "monopoly power of commercial publishers, combined with a third-party payment system, are at the heart of the problem." 22

\section{Experiences with DD/ILL}

Today, libraries are looking to remote access and DD to replace titles. A DD study at Auburn University's Veterinary Medical Library reported that 76 percent of the journals had only one article ordered from them, and only three percent had requests for more than five articles. The authors concluded that such frequency data aid the collection development (CD) process. ${ }^{23}$
The use of document delivery/interlibrary loan (DD/ILL) data for CD purposes was the topic of the 1993 ALA Collection Development and Evaluation Section (CODES) annual program. ${ }^{24}$ George Washington University reported that of 2,000 journals canceled, articles from only 300 of the titles were requested. Only 170 journal titles had more than one request resulting in a $\$ 300,000$ subscription saving and a $\$ 15,000$ DD expenditure. ${ }^{25}$ A Western Illinois University study reported that $\$ 177,000$ in subscriptions were canceled and $\$ 350$ expended on DD. ${ }^{26}$

Using ILL data for CD purposes is not new. The LSU Libraries, and other institutions, included it in collection decisions decades ago, but it is seldom reported in the literature. A 1993 study asserted that ILL statistics were valuable for monitoring collection strengths and weaknesses, making serial cuts, and purchasing monographs. ${ }^{27}$ In 1994 ALA recognized this role by stating that ILL is an "integral element of collection development for all libraries." 28

Today, many libraries use ILL/DD to extend resources. For libraries considering this option, Bazirjian's article raises important questions. ${ }^{29}$ Coons and McDonald pose criteria for substituting DD for subscriptions. ${ }^{30}$ Document Delivery Services: Issues and Answers takes the most comprehensive approach to DD versus ownership. ${ }^{31}$

Specific to LSU's first pilot is a University of Illinois Chemistry Library DD study which revealed that only 13 percent of the requests were for articles from canceled titles. ${ }^{32}$ The study concluded that the library should not reinstate canceled titles or add new ones due to the few times any journal title was requested. ${ }^{33}$ A Columbia University Libraries' study examined biology, physics, and electrical engineering information needs and concluded that "it is significantly less expensive to purchase periodical articles from document-delivery services or to borrow them through interlibrary loan than to buy them in anticipation of need." 


\begin{tabular}{|lcr|}
\hline \multicolumn{3}{|c|}{ TABLE 2 } \\
\hline \multicolumn{3}{|c|}{ History of Cancellations } \\
\hline Year & Titles & Amount \\
\hline 1986 & 47 & N/A \\
1987 & 83 & $\$ 45,460$ \\
1988 & 114 & $\$ 52,136$ \\
1989 & 420 & $\$ 92,166$ \\
$1990^{*}$ & 0 & 0 \\
$1991^{*}$ & 0 & 0 \\
1992 & 1,027 & $\$ 283,242$ \\
1993 & 471 & $\$ 129,747$ \\
1994 & 45 & $\$ 16,133$ \\
1995 & 332 & $\$ 120,001$ \\
1996 & 0 & 0 \\
\hline Totals & $\mathbf{2 , 5 3 9}$ & $\mathbf{\$ 7 3 8 , 8 8 5}$ \\
\hline * One-time bond money & \\
\hline
\end{tabular}

Various DD prices are quoted by McFarland, ranging from $\$ 9.50$ for regular delivery to $\$ 47$ for rush requests. ${ }^{34}$

\section{The Serials Environment at LSU}

From 1987 through 1991 three cancellation rounds had trimmed $\$ 200,000$ from the LSU materials budget (see table 2). More than $\$ 178,000$ in subscriptions were canceled in three reviews in the 1980s. Initially, faculty were circulated lists of titles costing \$200 or more and asked to identify serials for cancellation. The results were compiled and distributed for a second review. Faculty then were asked to prioritize titles: one for core titles, two for research titles, and three for peripheral titles. Many titles, marked for cancellation in the first review, received priority rankings in the second round. The conflicting results indicated that the process was not reliable for decisionmaking, but it was the only viable method at the time.

More cancellations followed in the early 1990s. Faculty feared that the collection's value was being diminished due to serials costs and declining book purchases. As serials expenditures ate into the materials budget, the Faculty Sen- ate Library Committee recommended that the libraries allocate one-third of the budget for books and the remainder for journals. Further cancellations were needed for book purchases, journal price increases, and new subscriptions.

During the fourth serials review in 1992, faculty were becoming indignant about the distributed journal lists. Asking faculty about their journal needs rather than using ratings was proposed. Initially viewed as impractical, the concept, which could lead to redesigning the journal collection, gained momentum. Though daunting for an institution with LSU's strong historical collections, subscriptions were absorbing nearly 100 percent of the materials budget. Chances for funding increases were remote.

As the 1992 serials picture worsened, more proposed cancellation lists were circulated. The lists were sent to deans and/ or department chairs in 1992, and Faculty Senate appearances were made to describe the worsening journals crisis. Dean Jennifer Cargill met with chairs in the colleges of agriculture and basic sciences, the departments most affected by upcoming cancellations which would bring total cuts to almost $\$ 500,000$. LSU's funding environment and Louisiana's continuing economic struggle eliminated prospects for added monies. The libraries' standstill budget had to be directed to the most cost-effective mix of article delivery and journal ownership.

In 1993, following numerous discussions and faculty input, and with the support of the Faculty Senate Library Committee, the libraries decided to test redesigning the journal collection. Concerned about continuing title cancellations, the Chemistry Department agreed to pilot the approach. The libraries had contracted for a standard UnCover gateway in late 1992 and intended to incorporate that access in the project.

\section{The LSU Document-Delivery Model}

After a year of planning, the LSU Libraries introduced the first pilot in April 1993 
to test the hypothesis that information needs could be met effectively and economically by integrating DD with CD activities. The libraries theorized that the savings resulting from substituting DD for canceled titles, plus savings in space, bindery costs, and serials staff, would more than offset subsidized DD costs. If the assumptions proved valid, the libraries would redefine the journal collection to provide a mix of subscription titles and articles delivered as needed. ${ }^{35}$

Traditionally, serials collections have been built by subscribing to titles that faculty and librarians considered essential for research libraries or for accreditation. The primary criterion for subscriptions often has been what the library "should" have, rather than what is "needed" by the university community. LSU's redesign plan would challenge that assumption by focusing on the relevance of journals to university programs. Therefore, research and instruction needs critical to the pilot's goals emphasized:

- improving access for faculty and graduate students to journal literature;

- redesigning the LSU journal collection by targeting titles meeting the university's current instruction and research needs.

It was theorized that a core of subscriptions would be essential to support users, but information defining the core could not be located in the literature or elsewhere. Library staff and the Senate Library Committee were concerned about utilizing DD and wanted answers to the following:

- Would DD allow the libraries to use funds more effectively?

- Would it meet needs for titles the libraries did not own?

- Would it provide effective access to canceled titles?

- Would faculty accept DD in lieu of subscriptions?

It also was essential that the pilot identify journals acceptable for DD. If successful and pursued campuswide, the pilot could lead to a comprehensive redesign of LSU's journal collection.

\section{The Chemistry Pilot}

Certain factors led to the Chemistry Department's participation in the first pilot. In 1989 chemistry faculty identified 410 subscriptions as "indispensable for research," at a total cost of $\$ 250,000$, higher than any other campus department. Chemistry is dependent on serials, and LSU chemists were alarmed by cancellations of titles they had deemed "essential."36 Campuswide cancellations now totaled $\$ 650,000$. Potentially, the chemistry pilot could provide the needed journal literature. The decision to conduct the pilot was not trivial for the department or the libraries.

Neil Kestner, then chair of the Chemistry Department, worked with the dean and investigators on documentation and needs assessment forms, and agreed to monitor faculty returns. In spring 1993, Kestner, Cargill, and the investigators introduced the pilot to one hundred chemistry faculty and graduate students. The UnCover system was demonstrated.

The LSU libraries selected UnCover as the primary supplier because it provided articles and tables of contents for more than 17,000 journal titles and promised an average 24-hour delivery time. The holdings were applicable to LSU's needs because 55 percent were scientific/techni$\mathrm{cal} /$ medical (STM) journals. The system had Boolean capabilities and, though "clunky," did not require sophisticated computer skills. Additionally, it offered UnCover Reveal, an alert service that permitted users to select journal titles, profile subject searches, and receive results by electronic mail. UnCover also served as an electronic index to 85 percent of LSU's serials resources and could be accessed from remote locations.

Free articles were provided for chemistry faculty and graduate students within defined parameters. Responsibility for DD was assigned to the Interlibrary Bor- 
rowing (ILB) Department where it meshed with traditional ILB services. Though subsidized, DD would eventually expand to all departments and use parameters would become more liberal; guidelines applied during the initial pilots focused on canceled titles and new journals.

As faculty and graduate students gained DD experience, their confidence in the pilot grew. At the same time, chemistry faculty were asked to list individually, in rank order, ten titles needed for teaching, ten for research, and ten for DD. Titles not owned could be included. The faculty was advised that a single department list would not be acceptable if the pilot were to provide meaningful data. The libraries planned to use the data to cancel titles identified for DD and to put some of the savings into new subscriptions.

\section{First Pilot Results}

The chemistry faculty listed 716 titles which resulted in 206 unique journals. The LSU libraries subscribed to 166 of the 206 journals. Faculty identified thirty-two subscription titles as amenable to DD which had been cited as essential for subscriptions six months earlier. Some fiftynine titles, identified by three or more faculty as critical for onsite access, suggested a chemistry journal core. Although faculty surveys had been conducted since 1987, this pilot provided the first empirical priority list of journals for that department.

A full one-third of the subscription titles were of interest to only one professor, which demonstrated the influence of single-faculty input on previous $C D$ decisions. That factor, plus the finding that 19 percent of the subscriptions were recommended for access via DD, indicated that titles with narrow scope could be considered for future cancellations. Investigators also learned that faculty could effectively differentiate between titles needed for onsite access and subscrip- tions and those where DD would be acceptable.

Chemistry faculty recommended forty new journals, but identified ten of those for DD. With the limited experience of the first pilot, faculty were demonstrating DD acceptance. The results of this pilot would not influence current cancellations because data from all departments using

\section{UnCover also served as an electronic index to 85 percent of LSU's serials resources and could be accessed from remote locations.}

chemistry journals were critical to these decisions. DD findings from the chemistry pilot were revealing, but not as significant as they would become as the project expanded. During April-June 1993, 199 ILB/DD orders were placed with 84 subsidized for DD (60 for faculty, 24 for graduate students). Other departments' orders were subsidized for titles within first-pilot parameters, and are reported in DD costs for the 42 months of the study.

As the chemists' positive reaction to DD and UnCover spread, other departments became interested. Library staff needed input from faculty using a broad range of journals and welcomed participation from the Department of Geography and Anthropology (G\&A) whose chair volunteered for the fall 1993 pilot.

\section{The Second Pilot}

In the 1989 serials review, G\&A faculty deemed 1,808 titles essential. Some 350 of them were unique to that discipline. Because G\&A targeted more "essential" journals than other departments, the faculty were each invited to list forty-five titles in assessment surveys in rank order.

The G\&A chair, the libraries' dean, and investigators described the project, demonstrated UnCover, and distributed sur- 
veys and documentation to forty G\&A faculty and graduate students in November 1993. After two months of testing DD/ILB support, faculty completed individualized journal needs assessments. Tabulated returns identified 535 journal titles as needed onsite. The libraries subscribed to 59 percent of that number. More important, the G\&A survey revealed that subscriptions for one-third of the titles reportedly supporting their discipline were not listed by any G\&A faculty. Some $\$ 17,740$ in subscription titles now identified for DD had been defended for retention in previous reviews. This freed one-third of G\&A expenditures for new subscriptions and future price increases. Further analysis identified a more diverse core journal collection than that of chemistry.

The G\&A department is less than half the size of LSU's chemistry unit and only ordered 162 articles in the first eight months. Two fell within initial DD parameters. Clearly, earlier cancellations had not hampered department programs. ${ }^{37}$

Faculty, research associates, and graduate students ordered 1,193 articles in the first fifteen months of UnCover use. Initial data revealed unexpected journal usage.

- A total of 1,193 articles were ordered from 540 different journal titles.

- Seven percent (82) of the articles were ordered from the same journal title three or more times.

- Three percent (41) were ordered from the same journal title four or more times.

- Less than one percent (17) were ordered from the same journal title ten or more times.

Requests indicated that even the most frequently ordered titles did not merit subscriptions because of the span of years required to fill the orders. Total article costs from frequently requested journals were far below subscription and backfile costs. Investigators theorized that the project would result in similar findings when expanded campuswide.

\section{Pilot Extended to All Sciences}

Because the initial pilots indicated that DD was more cost-effective than subscriptions for high-cost, low-use titles, the project was expanded to more than thirty science departments, research centers, and institutes. These were serials-oriented disciplines with the most inflated journal costs. This focus had the greatest potential for containing serials expenditures.

\section{Selectors}

In 1992 the libraries assigned CD decision-making to selectors. Previously, liaisons were reference librarians who worked with academic departments for communication purposes, online searching, and bibliographic instruction. With the addition of $\mathrm{CD}$ responsibilities, disciplines were reassigned to librarians in all departments and ranks, administrative to new hires. A year-long training program prepared them for their expanded roles.

By spring 1994, the libraries were ready to move into the sciences with the Serials Redesign program incorporating selectors. Because many were new to these activities, they needed training and support to participate. A successful program required the selectors to:

- sell the benefits of access when describing the initial pilots;

- provide consistent information to the academic departments;

- be confident when demonstrating UnCover;

- provide knowledgeable responses to questions.

To stress the importance of participation, the dean and/or investigators also attended the department meetings.

\section{Third Pilot Preparations}

The ensuing weeks were demanding for the Serials Redesign Task Force. The Dean and the LSU Vice-Chancellor for Academic Affairs met with deans and department chairs in the colleges and research centers to encourage participation. This phase included the Colleges of Agricul- 
ture, Basic Sciences, and Engineering; Mathematics and Kinesiology Departments located in other colleges (Arts and Sciences, and Education, respectively); and the research centers and institutes that reported to the Vice-Chancellor for Research and Economic Development.

A selectors" "redesign package" was developed including:

- a letter describing the project from the library dean;

- survey assessment forms to be used by faculty to list journals needed for research and instruction and for DD;

- findings from the first two pilots;

- CARL UnCover, a slide show created by Kleiner using multimedia presentation software;

- an overhead presentation for staff reluctant to use the CARL UnCover show;

- presentation narrative and notes for staff who prefer the lecture mode or to accompany CARL UnCover;

- project brochures and handouts;

- UnCover instructions specific to LSU facilities and services.

Training sessions for the selectors were held to familiarize them with the project and contents of the "redesign package." Collecting and analyzing faculty surveys dominated fiscal year (FY) 1995. Faculty were introduced to accessing journal literature via UnCover and utilizing the tables of contents service. They were asked to identify and rank journals within similar parameters used for earlier pilots.

During this same period, Cargill, Kleiner, and others were involved in a series of grant projects initiated in 1992 to upgrade Louisiana's academic library network, extend access statewide, and expand electronic resources for the Baton Rouge campus. These are summarized later in this paper.

\section{Science Pilot Results}

The ILB Department was dramatically impacted by the pilots. In FY95 DD use increased 122 percent; increases also occurred in traditional transactions. In the 3.5-year project, ILB had annual increases ranging from 33 percent one year to FY96's 25 percent increase. Staff were added to maintain fast turnaround of orders.

A total of 2,943 articles were received from DD suppliers in FY95. UnCover requests averaged 200 monthly, with an average article cost of $\$ 12.72$. The immediacy promise of an average 24-hour delivery time held constant for UnCover articles; 94 percent arrived in 24 hours. Results of a June 1996 UnCover time study are reflected in table 3 .

Other DD suppliers also were used. In FY95 orders went to the British Library Depository Supply Centre (BLDSC), University Microfilms Inc. (UMI), the Canada Institute for Scientific and Technical Information (CISTI), and the National Technical Information System (NTIS). A total of 856 requests was filled by these suppliers, approximately seventy per month, at an average cost of $\$ 14.43$ based on total charges for the four suppliers.

Of 700 faculty in LSU's sci-tech departments, 401 identified 2,689 titles for subscriptions. The libraries subscribed to 1,675 of the titles, more than 60 percent. Faculty identified 701 journals for DD. The most dramatic finding was that 800 sci-tech subscription journals were not 


\begin{tabular}{|lcrrr|}
\hline \multicolumn{4}{c}{ TABLE 4 } \\
\multicolumn{4}{c}{ Frequently Requested Titles/Costs FY95 } \\
\hline \hline & & & Total & \\
Journal Titles & Number & Copyright & Cost & Subscription \\
\hline Mechanism and Machine Theory & 10 & $\$ 70$ & $\$ 135$ & $\$ 900$ \\
Neuropsychiatry, Neuropsychology & 10 & $\$ 63$ & $\$ 128$ & $\$ 174$ \\
Neuroscience & 10 & $\$ 70$ & $\$ 135$ & $\$ 3,305$ \\
Science of the Total Environment & 10 & $\$ 70$ & $\$ 135$ & $\$ 2,387$ \\
Social Science and Medicine & 10 & $\$ 70$ & $\$ 135$ & $\$ 1,680$ \\
International Journal of Peptide & 11 & $\$ 113$ & $\$ 184$ & $\$ 520$ \\
Toxicology and Industrial Health & 11 & $\$ 36$ & $\$ 107$ & $\$ 168$ \\
Applied Catalysis. A, General & 12 & $\$ 84$ & $\$ 162$ & $\$ 2,921$ \\
Journal of Environmental Quality & 12 & $\$ 11$ & $\$ 89$ & $\$ 100$ \\
Personality \& Individual Differences & 12 & $\$ 84$ & $\$ 162$ & $\$ 710$ \\
Sensors and Actuators. Pt. B & 12 & $\$ 84$ & $\$ 162$ & $\$ 1,115$ \\
American Journal of Industrial Med. & 14 & $\$ 126$ & $\$ 217$ & $\$ 1,289$ \\
Psychopharmacology & 14 & $\$ 84$ & $\$ 175$ & $\$ 2,363$ \\
Environmental Toxicology \& Chem. & 16 & $\$ 112$ & $\$ 216$ & $\$ 515$ \\
Planta Medica (George Thieme) & 18 & $\$ 77$ & $\$ 194$ & $\$ 278$ \\
Scripta Metallurgica et Materialia & 23 & $\$ 161$ & $\$ 311$ & $\$ 570$ \\
Neuroscience Letters & 30 & $\$ 210$ & $\$ 405$ & $\$ 2,934$ \\
European Journal of Pharmacology & 37 & $\$ 259$ & $\$ 500$ & $\$ 4,222$ \\
Automatica & 54 & $\$ 378$ & $\$ 729$ & $\$ 985$ \\
Sensors and Actuators. Pt. A & 100 & $\$ 700$ & $\$ 1,350$ & $\$ 1,184$ \\
\hline Totals & 426 & $\$ 2,860$ & $\$ 5,631$ & $\$ 28,320$ \\
\hline
\end{tabular}

listed by any faculty. Another 296 subscription titles were recommended for DD. Because some of these could impact the social sciences, none would be moved to DD until completion of the social sciences pilot. Of the 1,000 new titles recommended for subscriptions, more than half were listed by one faculty member. Two or more faculty listed new titles for subscriptions, totaling $\$ 190,000$.

Utilizing the accumulated data, the work of redesigning LSU's journal collection began. For the first time in a decade, the libraries subscribed to 260 new journals, totaling $\$ 40,000$. And, for the first time since cancellations began in 1987, 300 subscriptions totaling $\$ 120,000$ were canceled without conflict.

\section{Cost-Effectiveness of DD Demonstrated}

In FY95 data revealed twenty titles as sources of articles requested ten or more times. Slightly more than 20 percent (426 of more than 2,000 articles) were ordered from the twenty titles listed in table 4. It would appear more cost-effective to subscribe to these titles, but pilot findings invalidate that assumption.

Total cost for the 426 articles was $\$ 5,629$, but a one-year subscription to the twenty journals totals $\$ 28,229$. Even requests for the most heavily ordered title, Sensors and Actuators, Pt. A, could not justify a subscription, though the cost of the title's FY95 requests exceeded the subscription price (cost of articles $=\$ 1,350$; one-year subscription $=\$ 1,184)$.

The one hundred articles ordered from Sensors and Actuators, Pt. A spanned five years, totaling $\$ 5,920$ for the subscription and backfile to fill the FY95 orders. Moreover, most of the articles were ordered by one individual. For 20 percent of the cu- 


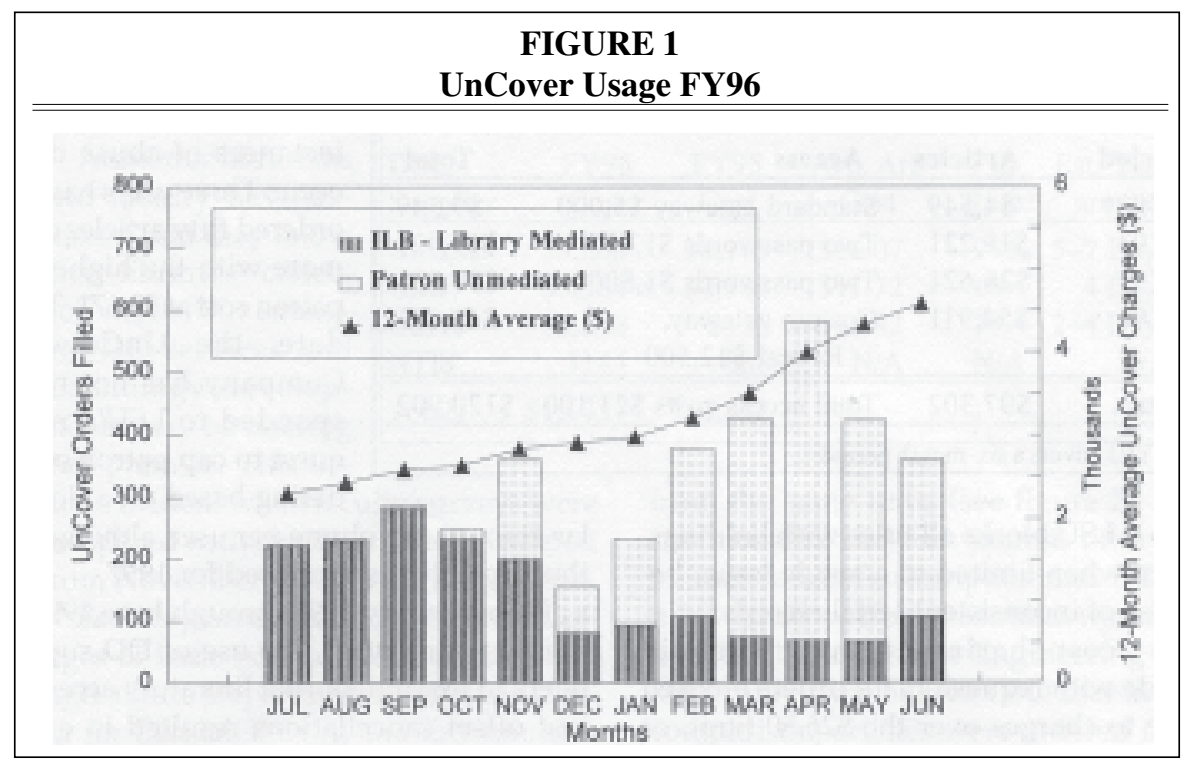

mulative subscription costs, needs were met promptly. This pattern held true for other heavily requested titles. The investigators established that DD is the most cost-effective solution for high-cost journals, even for titles ordered ten or more times.

\section{Introducing LSU UnCover}

After more than two years of DD use, library administrators agreed to test UnCover's Subsidized UnMediated Ordering (SUMO) gateway. The SUMO customized gateway enables subscribing libraries to define ordering parameters, load journal holdings, list call numbers, and define patrons; it also provides costaccounting detail if contracted. Dedicated ports ensure ready access.

User groups can be defined that enable patrons to order directly from UnCover after establishing personal profiles. Articles are transmitted to users' fax machines when machines are available round the clock, or to the library in the absence of 24-hour fax facilities. With SUMO and Reveal alert service site licenses, clients can order directly from Reveal search results. The LSU Libraries renamed the SUMO gateway LSU UnCover and established new parameters for subsidized unmediated ordering:

- eligible clientele include faculty, research associates, and graduate students;

- orders are blocked for all LSU journal titles;

- articles costing more than $\$ 26.50$ are blocked.

LSU UnCover offers third-party referral whereby clients can refer blocked orders to the libraries' ILB Department for the following reasons:

- LSU blocks all titles with holdings, even when limited to a single issue, because of inconsistent serial records;

- cost-sharing arrangements are made with requestors for orders blocked due to charges over the $\$ 26.50$ limit, or traditional ILB can be utilized.

Though undergraduates are excluded by client parameters, LSU UnCover benefits them too. With call numbers and holdings listed, LSU UnCover serves as an electronic index to 85 percent of the journal collection. Undergraduates also can order articles and charge them to credit cards, but when need for an article is justified, the libraries subsidize the request. 


\begin{tabular}{|lclr|}
\hline \multicolumn{4}{c|}{ TABLE 5 } \\
\hline \hline UnCover Cost History FY93-FY96 \\
\hline Period & Articles & Access & Total \\
\hline FY93* & $\$ 4,549$ & Standard gateway $\$ 5,000$ & $\$ 9,549$ \\
FY94 & $\$ 11,221$ & Two passwords $\$ 1,800$ & $\$ 13,021$ \\
FY95 & $\$ 26,621$ & Two passwords $\$ 1,800$ & $\$ 30,921$ \\
FY96 & $\$ 54,911$ & Custom gateway, & $\$ 67,411$ \\
& & Reveal $\$ 12,500$ & \\
\hline Totals & $\$ 97,302$ & Total access costs $\$ 21,100$ & $\$ 120,902$ \\
\hline$*$ FY93 covers a six-month period \\
\hline
\end{tabular}

DD costs many times.

LSU's average UnCover article cost was $\$ 12.75$ during the 42-month period of this study. In FY96 the average cost of librarymediated orders was \$14.26. Library-subsidized unmediated ordering by faculty, research associates, and graduate students us-

The LSU UnCover gateway was introduced in the fall of 1995. A task force designed customized screens, and LSU's patron file and journal holdings were loaded. Use began increasing by that November. By January 1996, unmediated orders surpassed library-placed requests. Figure 1 illustrates changes in unmediated versus ILB-initiated UnCover orders and average monthly article expenditures.

Most patrons use LSU UnCover responsibly; the median number of articles ordered per user is three with a median cost of $\$ 40$. However, instances of abuse do occur. Three users have ordered fifty articles or more with the highest patron

\section{Library-subsidized unmediated ordering by faculty, research associ- ates, and graduate students using the LSU gateway averaged $\$ \mathbf{1 3 . 8 6}$.}

cost at $\$ 2,671$. To date, the UnCover Company has not responded to LSU's request to cap patron ordering based on a dollar amount or volume per user, although this capability is promised for 1997 .

From January 1993 through June 1996 (forty-two months), the use of DD suppliers to expand journal literature access and offset cancellations resulted in expenditures of $\$ 136,641$ for all DD services. In FY95 total dollars recouped by the libraries from cancellations reached $\$ 738,885$ in annual expenditures recovered, offsetting ing the LSU gateway averaged \$13.86. Table 5 reflects expenditures for UnCover articles and services during the pilots. Total FY95 and FY96 costs for other suppliers are listed in table 6 .

\section{Journals Ordered versus Journals Recommended}

Building a journal collection is an enigma. No model can be devised suitable to all research institutions because each serves a unique community. Academic libraries have valid concerns about underutilized costly materials. Studies reveal that less than 60 percent of research libraries' holdings circulate, and 80 percent of those are checked out soon after purchase. ${ }^{38}$ Yet, libraries have continued to buy costly materials and pressure university administrators for more space in which to house them.

Academic librarians and faculty have assumed that they know their libraries' collection needs, but emerging DD services and technology developments may be altering that premise. This became evident when faculty surveys were compared with UnCover articles ordered from November 1995 through May 1996.

Faculty journal needs lists from the Colleges of Basic Sciences, Engineering, and Agriculture Departments, ${ }^{39}$ plus the Center for Coastal, Energy, and Environmental Resources (CCEER), were matched with orders placed by UnCover clients from the same units (see figure 2). The commonality between journal titles recommended for 
subscription and DD articles requested from those titles was minimal. In the Industrial Engineering (IE) Department, the heaviest DD user in this comparison, articles were ordered from 102 journals; only 48 titles were recommended for sub-

\begin{tabular}{|lrrrrr|}
\hline \multicolumn{7}{c|}{ TABLE 6 } \\
Other DDS Costs, Data \\
\hline \hline DDS & FY96 & FY95 & Avg. Art. & Fill & Est. Turn- \\
Supplier & Cost & Cost & Cost & Rate & around \\
\hline BLDSC & $\$ 8,833$ & $\$ 8,175$ & $\$ 16.07$ & $91 \%$ & $5-7$ Days \\
UMI & $\$ 3,584$ & $\$ 3,584$ & $\$ 11.72$ & 69 & 4 Days \\
CISTI & $\$ 3,248$ & $\$ 525$ & $\$ 13.82$ & 79 & 2-4 Days \\
NTIS & $\$ 144$ & $\$ 68$ & N/A & N/A & N/A \\
\hline Totals & $\$ 15,737$ & $\$ 12,352$ & & & \\
\hline
\end{tabular}
scriptions. The comparison study revealed only three common journal titles, meaning they appeared on faculty lists and were the source of DD orders placed during the study.

Chemistry, the first pilot department and second heaviest UnCover user, ordered articles from sixty-one journals. Chemists listed forty-two journal titles for subscription, but orders for articles from only nine journals

were in common. Similar patterns were reflected in other departmental comparisons. It appears that greater access to the literature afforded by alert services, electronic indexes and abstracts, and other digitized resources increases the range of journals used by researchers beyond their own expectations and those of academic librarians.

In a 1995 article, Philip Barden of the

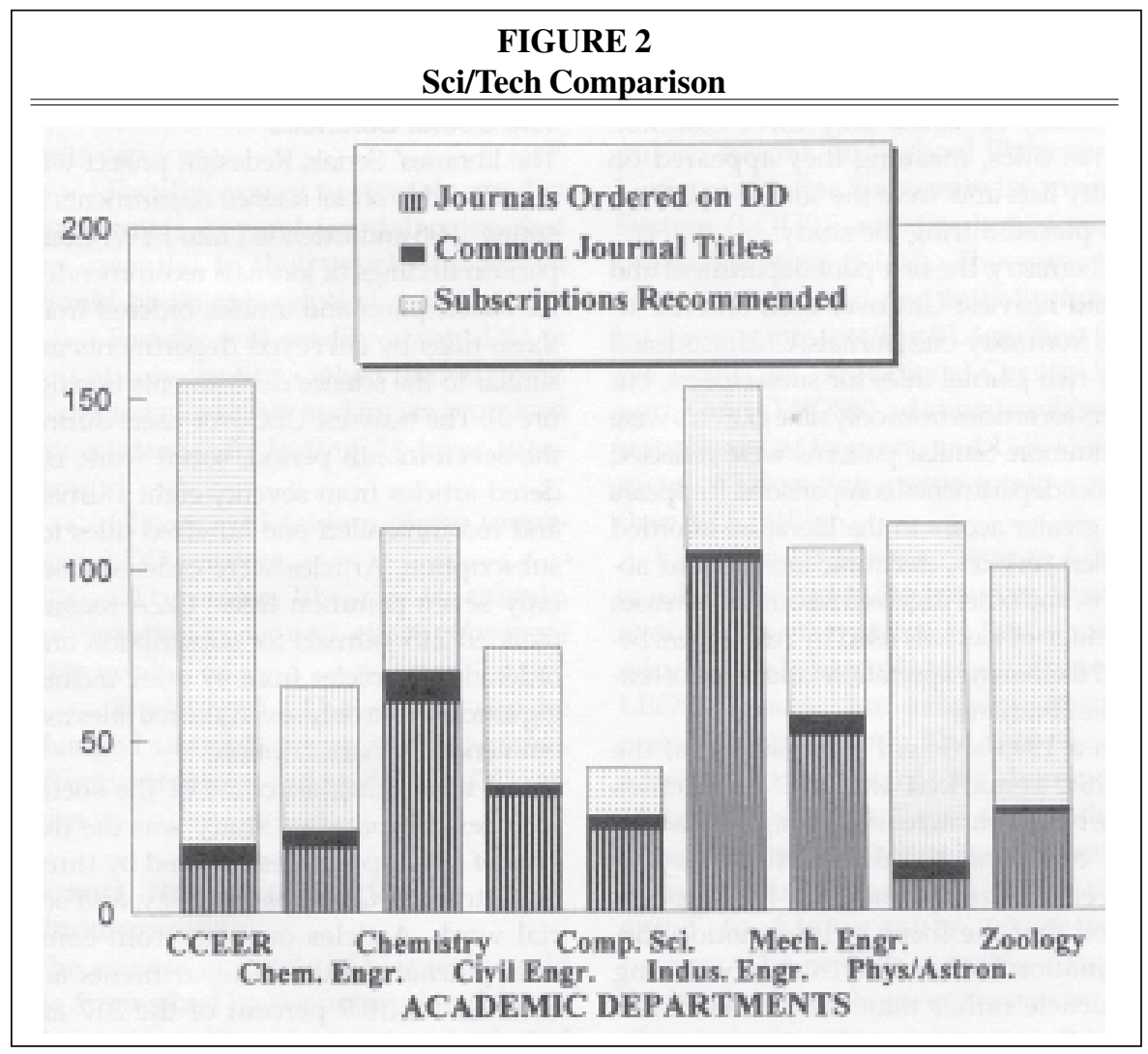




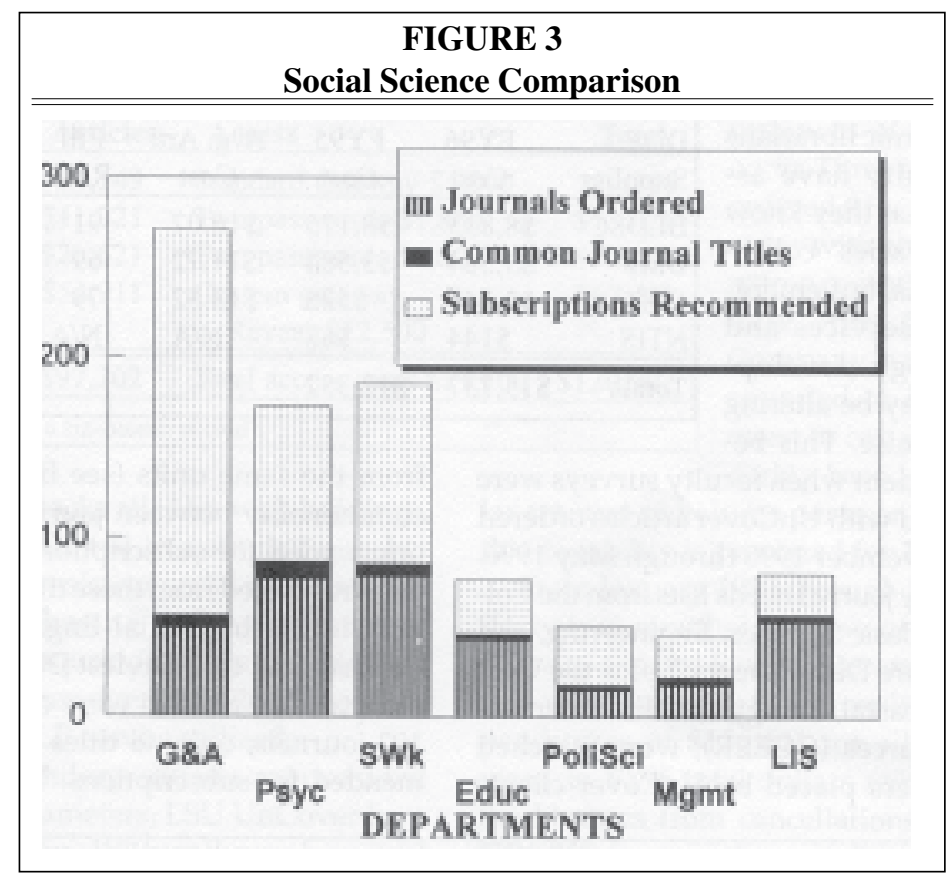

BLDSC remarked that DD economics were based on increasingly high subscription costs and the diminishing buying power of library budgets. He hypothesized that the focus of information dissemination in the sciences was becoming the article rather than the journal. ${ }^{40}$ The LSU pilots corroborate his theory.

\section{The Social Sciences}

The libraries' Serials Redesign project was introduced to social science departments in spring 1996 and extended into FY97. Comparison findings of journals recommended for subscription and articles ordered from those titles by surveyed departments are similar to the science departments (see figure 3). The heaviest UnCover users during the sevenmonth period, social work, ordered articles from seventy-eight journals and recommended one hundred titles for subscription. Articles were ordered from only seven common titles. G\&A recommended 215 journals for subscription and ordered DD articles from 49 titles, including articles from only seven journal titles recommended for subscription.
An interesting outcome of the social sciences comparative study was the degree of overlap in titles ordered by three departments: G\&A, psychology, and social work. Articles ordered from common journals in these departments accounted for 18.9 percent of the 317 articles ordered by the three faculties. This indicates that the value of the social sciences investigation is in determining interdisciplinary journals commonly needed, rather than in replacing titles with DD.

\section{Experiential Findings}

Although the social sciences pilot is still in progress and the humanities pilot just beginning, four years of data and considerable anecdotal evidence have led to the following conclusions, which are expected to remain valid throughout the project:

- It is more economical to use DD for high-cost, low-use journals than to subscribe to them.

- Faculty and graduate students can 
work effectively with fewer journal subscriptions than they or library staff expected.

- Most clients prefer direct ordering and delivery without library intervention.

- Clients like and use tables of contents services.

- Faculty cannot accurately predict the journals, beyond a certain core, that are essential to their work and which should be on subscription.

- Faculty will readily accept DD in lieu of subscriptions when the service is marketed effectively and meets promised expectations, including 24-hour turnaround.

- Clients will seldom abuse unmediated DD services.

- DD permits libraries to contain subscription costs and effectively meet user needs.

- Traditional CD concepts can be changed through orientation programs, effective training, and an efficient DD service.

\section{Grants, Networks, and the Undergraduate}

The success of LSU's DD projects could be diminished by the perception that undergraduate library needs are neglected in favor of faculty and graduate students because undergraduate orders are not routinely subsidized. Most canceled subscriptions, however, were expensive research titles and generally not used by undergraduates. Also, the LSU Libraries, by partnering with other academic departments and libraries, have expanded electronic resources statewide utilizing grant funds.

Due to this article's focus on DD and Serials Redesign, the grant efforts are summarized because of their significance in expanding information resources, including full-text databases. Several articles have been written describing LSU grant projects. ${ }^{41}$ The funded projects and suggestions for proposal development also were the subject of a presentation at the April 1997 ACRL National Conference. $^{42}$

In 1991 the LSU Libraries began seeking external funding. Louisiana now has two electronic library networks that have united the resources of 105 academic, public, special, and school libraries: the Louisiana Online University Information System (LOUIS) and the Louisiana Library Network (LLN). These projects were implemented and initially funded by three grants totaling $\$ 1.4$ million from the Louisiana Educational Quality Support Fund (LEQSF) administered by the state Board of Regents, and U.S. Department of Education grants totaling more than \$2.6 million.

LEQSF awards are unique to Louisiana, but similar funding sources often are available in other states. In Louisiana, all educational institutions compete for LEQSF awards, but academic libraries cannot apply directly. The LSU libraries achieved their awards by developing partnerships with colleges and academic departments on campus and across the state. Funding comes from a trust dedicated to high-quality educational projects. The process is highly competitive, and proposals are evaluated by out-of-state reviewers.

Network communication costs have been reduced by an educational tariff approved by the Louisiana Public Services Commission. This provided a $\$ 5.6$ million rate reduction for networked libraries and ongoing annual reductions of $\$ 1.2$ million. In 1996 the Louisiana legislature approved annual funding of $\$ 1,085,000$ for network support. State funding increased to $\$ 1.5$ million in FY 1997.

LOUIS and LLN have expanded electronic resources and provided Internet access for participating institutions and the general public. Equipment and staff are housed at LSU for this joint project of the libraries and the LSU Division of Computing Services. Constituents include the State Library of Louisiana, four higher education boards, sixteen colleges 
and universities, twenty public and private $\mathrm{K}-12$ schools, and sixty-six independent public library systems.

The network subscribes to twenty-nine electronic indexes and abstracts and to fulltext products providing articles from more than one thousand periodicals. The fulltext license covers unlimited downloading and/or printing of articles. The indexes and abstracts access thousands of general and academic journals, as well as newspapers. Access to specialized indexes for engineering, biology, agriculture, education, and other disciplines are subsidized by either initial grants or recent awards to the LSU Libraries.

Current awards support a Coastal Studies project and two electronic classrooms to support hands-on instruction. The university, in tandem with Computing Services, also is funding a third electronic classroom and more than a hundred high-

\section{Grant awards have opened a new electronic universe for LSU users.}

end workstations to be installed in three new library computing laboratories.

At the same time, the LSU Digital Library is capturing the works of distinguished faculty and other institutional assets. Mississippi River photographs are being digitized in the Coastal Studies project. The libraries' Special Collections project on Louisiana Native Americans will build on this architecture. Currently, the project is being developed within the LSU Intranet, but subsequent phases will target full Internet access.

Most recently, the federal education office awarded the network an additional million dollars for retrospective conversion, digital library initiatives, to begin developing distance education library resources and electronic reserve capabilities, as well as other activities. These projects will be implemented in the year ahead.

Grant awards have opened a new electronic universe for LSU users. The classrooms will ensure that undergraduates and others get the hands-on experience essential to accessing campus and Internet information. The latest award will boost current activities, extend training for users and public and school library staff, and begin developing information resources to support distance learning.

Due to the successes of the grantfunded programs, the DD pilots, Serials Redesign, the networks, and the digital project, LSU is positioned to move into the twenty-first century. These achievements persuaded state legislators to appropriate and increase funding for continued network support and the university to fund new library computing facilities. Most important, these resources will enable the academic community and the state's citizens to make a successful transition to the new millennium. Libraries 2000 is a reality at LSU, and it has been achieved without a great outpouring of university funds in a state battling economic reverses.

\section{Initiating DD/Serials Redesign Projects}

Effectively integrating DD into libraries' $\mathrm{CD}$ activities and redesigning traditional journal collections require planning and organized implementation. Activities that led to LSU's success are proposed for other institutions interested in adapting this model. These include:

\section{Obtain the support of the university administration.}

a. Provide administrators with a summary of problems impeding traditional CD practices and options to offset the problems.

b. Educate appropriate university groups about the pricing crises.

\section{Enlist the aid of deans, directors, and department heads to embark on a DD trial.}

a. Gain faculty advocates by involv- 
ing them in the process; this is more easily achieved with the support of the university administration.

b. Invite investigators from other universities' successful programs to present their data and entertain questions at a seminar for university leaders.

\section{Enlist campuswide cooperation in support of document delivery.}

a. Initiate a pilot or series of pilots in academic departments.

b. Collect and analyze pilot data to pique interest and obtain cooperation from other academic departments.

c. Provide faculty with data and summarize and cite research from the literature describing similar projects.

\section{Assign DD responsibility to an effec- tive library department.}

a. The project's success depends on efficiency and fast turnaround of orders.

b. The library should deliver what is promised, which relies on staff and DD supplier performance.

\section{Design a proactive program to intro-} duce DD as a collections component.

a. Appoint a task force to be responsible for program components.

b. When possible, include academic department chairs in developing orientation programs, at least initially.

\section{Market the program to the campus.}

a. Develop and provide library staff with tools essential to successful presentations such as presentation software, equipment, slide shows, documentation, etc.

b. Plan the most effective means of establishing and implementing the program in keeping with an activities time line.

c. Provide faculty with selectors' email addresses and telephone and fax numbers to provide support should questions arise or faculty/students encounter problems.
7. Prepare selectors to participate in the project.

a. Familiarize staff with documentation, data, and literature relevant to similar projects.

b. A computer-based presentation provides an effective introduction and ensures consistent information. Overheads, narratives, outlines, notes, and other information should be available to participating staff.

c. Train presenters to use the primary DD system and inform them about other DD suppliers.

d. If the primary DD system utilizes user profiles, require presenters to establish them to gain system experience.

e. Schedule presentations at academic faculty meetings to promote the program and provide an arena to address concerns.

f. At least one experienced task force member should attend faculty meetings with the presenter(s).

8. If the library elects to assess faculty journal needs, it is beneficial to involve the department chair in the process.

a. Simple and direct survey forms should be provided.

b. For a valid journal needs assessment, faculty must complete the forms individually; do not accept departmental assessments.

c. Invite the department chair to take responsibility for collecting the surveys and forwarding them to the library.

9. If journal needs surveys are conducted, the library should establish procedures for tabulating and analyzing the data.

a. Identify staff, hardware, and software to handle data.

b. Design models to build and analyze the serials database. (LSU uses Access, but other packages are available.)

10. Collect, analyze, and report results to faculty, administrators, the university at large, and the profession.

a. Present and update data in campus publications. 
b. Use a library publication, or develop one if needed, to keep the university community informed about the project.

c. Publish findings in the professional literature.

\section{Conclusion}

Today's academic libraries must examine existing practices, implement changes, streamline procedures, improve access, and seek creative funding options. Librarians must become entrepreneurs abandoning "safe" approaches for innovative solutions.

Demands for information in electronic and developing formats are forcing libraries to budget to support new technologies while continuing funding for traditional collections. Funds can be maximized by redirecting traditional journal collections to target current research and instruction needs by using DD to supplement collections.

Commercial DD and tables of contents alert services expand journal resources cost-effectively. Libraries can cancel highcost, low-use journals without impeding information access and free dollars for other uses.

Through periodic assessments of faculty journal needs and ongoing analyses of DD use, libraries can design dynamic collections for the changing needs of users. Journal expenditures can be contained and access to literature increased. Subsidized unmediated ordering of journal articles, within defined parameters, offers firsthand evidence of the fast turnaround provided by some DD suppliers. This ensures user satisfaction and reduces staff time required for mediated ordering.

In conjunction with these activities, librarians must seek new funding sources in this prevailing climate of static budgets. One largely untapped resource is through grants. Federal, state, private, and corporate dollars are available and the agencies receptive to shared resources projects. Libraries must partner with other campus units, institutions, and the corporate world to improve funding opportunities. Librarians need to develop skills to compete successfully in the grants' marketplace.

Research libraries can no longer succumb to tradition. They must take risks, test different methods of information dissemination, and seek new remedies for old problems. As the new millennium approaches, members of the profession must begin transforming today's traditional research libraries into the client-focused information centers of tomorrow.

\section{Notes}

1. States in Profile: The State Policy Reference Book (McConnellsburg, PA.: State Policy Research, 1991).

2. U.S. Bureau of the Census, 1990 Current Population Survey (Washington, D.C.: U.S. Bureau of the Census, 1990).

3. The 1996-97 LSU General Catalog 88 (April 1996): 9-11.

4. Ibid.

5. Concept stated in a resolution passed by ALA Council in San Francisco, June 1987, entitled Impact of Dollar Devaluation, sponsored by the Resources and Technical Services Division of ALA, and introduced at the behest of the Chief Collection Development Officers of Large Research Libraries Discussion Group.

6. Robert G. Sewell, "Library Materials Budget Survey: Source of Funds and New Commitments," ARL Newsletter 182 (Oct. 1995): 8-9.

7. Ibid., 8-9.

8. Comparison of the 1986 and 1987 price lists for Elsevier Sequoia, Elsevier Scientific, and Elsevier U.S.

9. Anna H. Perrault, "The Changing Print Resource Base of Academic Libraries in the United States," Journal of Education for Library and Information Science 36 (fall 1995): 295-305, based on Perrault's Ph.D. dissertation, The Changing Print Resource Base of Academic Libraries in the United States: A Comparison of Collection Patterns in Seventy-Two ARL Academic Libraries of Non-serial Imprints for the Years 1985 and 1989 (Florida State University, 1994). 
10. Association of Research Libraries, ARL Statistics 1994-95: A Compilation of Statistics from the One Hundred and Nineteen Members of the Association of Research Libraries (Washington, D.C.: ARL, 1996), 10-11.

11. Deana Astle and Charles Hamaker, "Journal Publishing: Pricing and Structural Issues in the 1930s and the 1980s," in Advances in Serials Management: A Research Annual 2 (Greenwich, Conn.: JAI Press, 1988), 1-36.

12. Lewis Pyenson, Cultural Imperialism and Exact Sciences: German Expansion Overseas 19001930 (New York: Peter Lang, 1985), 211.

13. M. Llewellyn Raney, "Foreign Exchange," Library Journal 45, no. 6 (Mar. 15, 1920): 256; "Editorial," Library Journal 45, no. 10 (May 15, 1920): 454.

14. Charles Harvey Brown, "Bringing the Periodical Situation Up to Date," ALA Bulletin 27, no. 9 (Sept. 1933): 379.

15. —— "Discussion on German Periodicals," Library Journal 58, no. 21 (Dec. 1, 1933): 978.

16. Charles Bourne and Dorothy Gregor, "Methodology and Background Information to Assist the Planning of Serials Cancellations and Cooperative Serials Collections in the Health Sciences," ERIC report ED 104-409 (Berkeley: Institute for Library Research, University of California, Jan. 1975).

17. Papers by Charles Hamaker and others, presented at the North American Serials Interest Group (NASIG) Conference at Dennison University, Granville, Ohio, June 1987.

18. Astle and Hamaker, "Journal Publishing," 13.

19. Ibid., 14.

20. Ibid., 18-19.

21. Lionel Standing and Stuart McKelvie, quoted in Chronicle of Higher Education 33, no. 23 (Feb. 18, 1987): 6.

22. Michael A. Stoller, Robert Christopherson, and Michael Miranda, "The Economics of Professional Journal Pricing," College \& Research Libraries 57 (Jan. 1996): 9-21.

23. Tamara P. Lee and Lawrence J. Myers, "Document Delivery at a Veterinary Medical Library: A One-Year Study of Use Patterns," Collection Management 16, no. 2 (1992): 75-92.

24. The conference programs were reviewed by Lynne C. Branch in "Document Delivery: Where Collection Development and ILL Meet: An RASD Collection Development and Evaluation Section Program," Library Acquisitions: Practice and Theory 18, no. 1 (spring 1994): 96-97.

25. Ibid.

26. Ibid., 97.

27. Mounir A. Khalil, "Applications of an Automated ILL Statistical Analysis As a Collection Development Tool," Journal of Interlibrary Loan, Document Delivery \& Information Supply 4, no. 1 (1993): 45-54.

28. American Library Association, Reference and Adult Services Division, Management and Operation of Public Services Section, Interlibrary Loan Committee, "National Interlibrary Loan Code for the United States 1993," $R Q$ 33, no. 4 (summer 1994): 477-79.

29. Rosann Bazirjian, "A Charmed Brew: Document Delivery and Collection Development in the Fast Lane," Collection Management 19, no. 3/4 (1995): 7-10.

30. Bill Coons and Peter McDonald, "Implications of Commercial Document Delivery," College \& Research Libraries News 56, no. 9 (Oct. 1995): 626-31.

31. Eleanor Mitchell and Sheila A. Walters, Document Delivery Services: Issues and Answers (Medford, N. J.: Learned Information, 1995).

32. Tina E. Chrzastowski and Mary A. Anthes, "Seeking the $99 \%$ Chemistry Library: Extending the Serial Collection through the Use of Decentralized Document Delivery," Library Acquisitions: Practice and Theory 19, no. 2 (summer 1995): 141-52.

33. Ibid., 149.

34. Robert T. McFarland, "A Comparison of Science Related Document Delivery Services," Science and Technology Libraries 13 (fall 1992): 115-44.

35. Charles A. Hamaker, "Redesigning Research Libraries: First Steps toward the 21st Century," Journal of Library Administration 22, no. 4 (1996): 33-48 96.

36. Charles Harvey Brown, Scientific Serials, ACRL monograph no. 16 (Chicago: ACRL, 1956),

37. Information on the two pilots is gleaned from internal reports and from the paper by Charles A. Hamaker, "Re-designing Serial Collections," Journal of Library Administration 20, no. 1 (1994): 37-47.

38. Paul Evan Peters, "Networked Information Resources and Services: Next Steps," Cause/ Effect 14 (summer, 1991): 27-29, 33-39.

39. Debra L. Currie, "Serials Redesign: Using Electronic Document Delivery to Reshape Ac- 
cess to Agriculture Journal Literature," Journal of Agricultural and Food Information 3, no. 2 (1995): $13-22$.

40. Philip Barden, "Multimedia Document Delivery-The Birth of a New Industry," Online \& CD-ROM Review 19 (Dec. 1995): 321-23.

41. Jennifer Cargill, "A Target of Opportunity: Creation of the LOUIS Network," Library Hi Tech 13, no. 1-2 (1995): 87; "Library Consortia for the 90s," LITA Newsletter 16 (fall 1995): 9; Karen Cummings, "Louisiana's Window to the World," Computers in Libraries 15, no. 6 (June 1995); "LOUIS Update," LLA Bulletin 57 (spring 1995): 245; Nancy Nuckles, "Louisiana Network Links Libraries," College \& Research Libraries News 55 (July/Aug. 1994): 414-15; "LANET Linking Louisiana," Government Technology 7 (Mar. 1994): 12-13; U.S. Department of Education, Office of Research and Improvement, Library Programs, "Library Grant Helps Louisiana on to the Information Superhighway," LP-94-4002 (Jan. 1994); Jennifer Cargill and Ronald D. Hay, "Achieving a Vision of a Statewide Academic Library Network," Journal of Academic Librarianship 19 (Jan. 1994): 386-87; "Louisiana to Improve Networks," College \& Research Libraries News 54 (Dec. 1993): 627; "Network Funded by U.S. Dept. of Ed.: State University and Agricultural College Receives \$2.5 Million," Library Journal 118 (Nov. 1993): 18.

42. Jane P. Kleiner, "Grants, Networks, and Partnerships" (paper presented at the panel Reinventing Libraries 2000: A New Paradigm for Academia . . . The LSU Experience, ACRL 8th National Conference, Nashville, April 1997). 